(Aus der Universitäts-Augenklinik zu Heidelberg)

\title{
Notiz über spontane Lochbildung in der Fovea centralis.
}

$$
\text { Von }
$$

Prof. Eugen v. Hippel.

Mit Taf. V, Fig. 1 u. 2.

Die Arbeit von Reis ${ }^{1}$ gibt mir Veranlassung, einen Befund kurz zu beschreiben und abzubilden, welcher dem von $\mathrm{Fuchs}^{2}$ ) veröffentlichten im wesentlichen gleicht und sich von demselben nur dalurch unterscheidet, dass in meinem Falle kein Trauma vorliegt.

Derselbe betrifft eine 59 jährige Patientin und ist bereits in meiner Arbeit über die Ergebnisse meiner Fluoresceinmethode ${ }^{3}$ ) mitgeteilt, ich kann mich deshalb auf die Schilderung des Befundes an der Fovea beschränken.

An den Rändern derselben zeigt die innere Körner- und Ganglienzellenschicht die normale Dickenzunahme. In der inneren Körnerschicht, sowie in der Schicht der Zapfenfasern sind die Netzhautelemente durch Hohlräume auseinandergedrängt, welche mit einer durch die Härtung in wabenartiger Anordnung geronnenen Flüssigkeit ausgefüllt sind. Die innere Körnerschicht ist dadurch stellenweise in zwei Blätter gespalten. In der Fovea selber befindet sich ein grosser mit Flüssigkeit gefüllter Raum, der vom Glaskörper nur durch die vorgewölbte Limitans interna' getrennt ist, während ihn nach hinten eine schmale Lage von Netzhautgewebe begrenzt. Letztere besteht ausschliesslich aus gewucherter Stützsubstanz mit vereinzelten pigmentierten Zellen, während äussere Körner mit Zapfen

1) Reis, Zur Atiologie der Lochbildung in der Macula lutea. Zeitschr. f. Augenheilk. Bd. XV. 1. S. 37.

2) Fuchs, Zur Veränderung der Macula lutea nach Kontusion. Zeitschr. f. Augenheilk. Bd. IV.

3) E. v. Hippel, Die Ergebnisse meiner Fluoresceinmethode. v. Graefe's Arch. f. Ophthalm. Bd. LIV. S. 537. 
an dieser Stelle vollkommen fehlen und erst wieder zu den Seiten der Fovea auftreten (Fig. 1). Das Pigmentepithel zeigt im Bereiche der Fovea ausgesprochene Unregelmässigkeiten und kleine Defekte; es ist überall von der flach - artifiziell - abgelösten Retina durch einen schmalen Spalt getrennt.

In der Gegend des ganzen hinteren Pols fällt an der Retina noch eine gewisse Unregelmässigkeit in der Dicke der einzelnen Schichten, sowie das Auftreten massenhafter Zellkerne in der Zwischenkörnerschicht auf. Dieselben sind länglich und stehen mit der Achse senkrecht zur Oberfläche der Retina. Sie färben sich mit Hämatoxylin erheblich schwächer als die Zellen der Körnerschichten und können wohl nur auf eine Proliferation der Glia bezogen werden.

Die Limitans interna ist auf grosse Strecken und zwar nicht nur in der Gegend der Fovea durch feinkörnige Massen arkadenartig von der Retina abgehoben, man sieht die abgerissenen Enden der retinalen Gewebselemente in diese Hohlräume hineinragen. Ich halte diesen Befund, da ich ihn von zweifellos normalen Augen her kenne, mit überwiegender Wahrscheinlichkeit für ein Kunstprodukt und lege ihm deshalb keinen Wert bei. In der Foveagegend, sowie an vielen andern Stellen, aber nicht nachweisbar kontinuierlich, findet man ein der Limitans interna aufgelagertes, sehr zartes endothelartiges Häutchen, wie es schon vielfach beschrieben wurde.

Eine systematische Untersuchung der Netzhautgefässe an Serienschnitten liegt nicht vor, doch lässt sich sowohl an kleinen wie an grösseren Gefässen - vorwiegend arteriellen - eine sehr ausgesprochene Wandverdickung mit Verengerung des Lumens und stellenweise hyaliner Degeneration der Wandung nachweisen. Fig. 2 gibt einen Durchschnitt durch ein solches Gefäss (zwischen Papille und Fovea).

Die Glaslamelle der Chorioidea ist auffallend dick, die Struktur der Aderhaut durchaus normal, nirgends hesteht eine Verwachsung zwischen Retina und Chorioidea, der Blutgehalt der letzteren ist sehr erheblich, die Gefässe zeigen im allgemeinen normales Verhalten, nur. in der Gegend der Fovea haben einzelne eine auffallend dicke, stark lichtbrechende Wandung (hyaline Degeneration).

Wir baben also in der Gegend der Fovea und zwar ausschliesslich an dieser Stelle ein hochgradiges Netzhautödem, das nach den Rändern der Fovea hin an Ausdehnung abnimmt, in der Fovea selbst aber eine grosse von Flüssigkeit erfüllte Höhle bildet, die vom Glaskörperraum nur durch die Limitans, nach aussen durch eine ganz 
174 E. v. Hippel, Notiz über spontane Lochbildung in der Fovea centralis.

dünne Lage neugebildeten Gliagewebes abgeschlossen ist. $\mathrm{Ob}$ hier noch eine vollständige Perforation der Netzhaut erfolgt wäre, ist natürlich nicht zu entscheiden, aber auch bei späterer Resorption der Flüssigkeit hätte wohl ein Bild entstehen können, wie es ophthalmoskopisch als Lochbildung der Fovea beschrieben ist. Ich verweise in dieser Beziehung auf die Ausführungen von $\mathrm{Fuchs}^{1}$ ), denen ich nichts zuzufügen habe.

Leider fehlt auch in meinem Falle der ophthalmoskopische Befund, da die brechenden Medien undurchsichtig waren.

Das Ödem der Fovealgegend ist nicht auf ein Trauma zu beziehen, sondern mit grösster Wahrscheinlichkeit auf die Erkrankung der Netzhautgefässe. Die Identität der anatomischen Befunde von. Fuchs und mir spricht entschieden für die von Reis vertretene Ansicht, dass sowohl in den Fällen traumatischer wie auch spontaner Lochbildung in der Maculagegend ein starkes Ödem derselben als das primäre anzusehen ist.

Zur Ergänzung der von Reis gegebenen Literaturübersicht möchte ich noch darauf hinweisen, dass von $\mathrm{Nuel}^{2}$ ) die Erkrankungen der Macula pathologisch-anatomisch näher studiert worden sind und dass auch er bereits von Lochbildung an dieser Stelle infolge starken Ödems gesprochen hat. Seine Abbildungen sind leider sehr schematisch und die Präparate offenbar nicht frei von Kunstprodukten, ich glaube dass z. B. beim Zustandekommen eines Bildes, wie es Fig. 5 zeigt, artifizielle Veränderungen mit in Betracht gezogen werden müssen, das Wesentliche der Ausfihrungen $\mathrm{Nu}$ els bleibt dadurch aber wohl unberiihrt.

\section{Erklärung der Abbildungen auf Taf. V, Fig. 1 u. 2.}

Fig. 1. Grosser von Flüssigkeît gefüllter Hohlraum in der Fovea; ein ganz zartes Häutchen schliesst denselben gegen den Glaskörper ab. Fehlen der Zapfen und äusseren Körner in der Mitte der Fovea. Hoblräume und zahlreiche Zellkerne in der Zwischenkörnerschicht.

Fig. 2. Gefäss mit hochgradiger Wandverdickung zwischen Papille und Fovea.

1) Loc. cit.

3) $\mathrm{Nuel}$, Altération de la macula lutea. Arch. d'Ophtalm. Tom. XV. p. 593. Tom. XVI. p. 145 u. 473. 

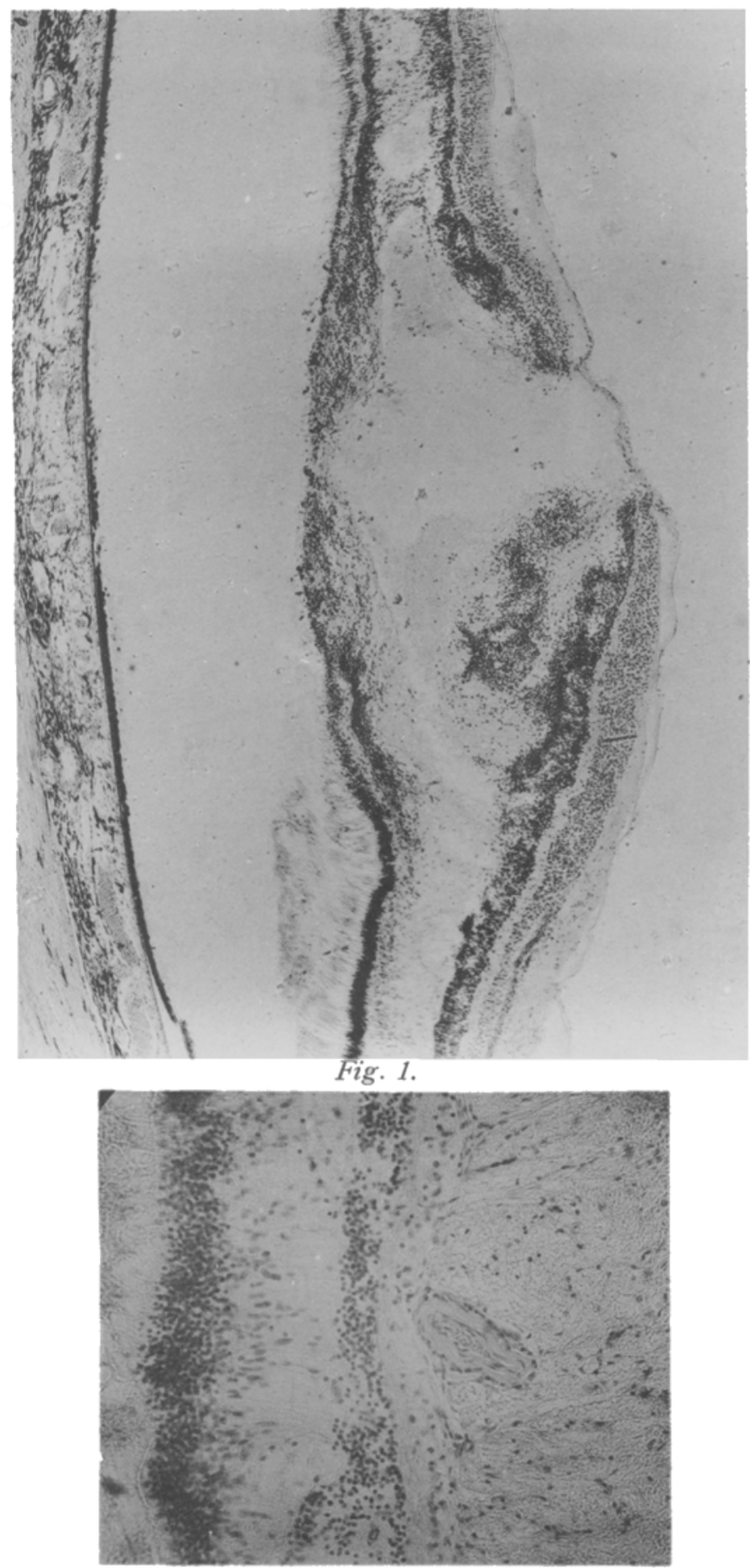

Fig. 2.

Lichtaruč von C. G. Rödex G. m. b. H., Leipzig. 